\title{
Fractionation of Guinea Pig Serum for an Inducer of Gonococcal Resistance to Killing by Human Serum: Active Fractions Containing Glucopeptides Similar to Those from Human Red Blood Cells
}

\author{
By P. V. PATEL, ' D. R. VEALE, ' J. E. FOX, ' P. M. V. MARTIN, ${ }^{3}$ \\ N. J. PARSONS ${ }^{\prime}$ AND H. SMITH ${ }^{1 *}$ \\ 'Department of Microbiology and 2 Macromolecular Analysis Sertice, University of Birmingham. \\ PO Box 363, Birmingham B15 2TT. UK \\ ${ }^{3}$ Unité d'Ecologie bactérienne, Institut Pasteur, 75015, Paris, France
}

(Received 19 March. 1984; revised 5 June 1984)

\begin{abstract}
The resistance of gonococci to complement-mediated killing by serum is important in the pathogenesis of gonorrhoea. Most urethal strains lose this resistance on subculture. The host product(s) which induces the resistance in vivo is therefore fundamental to pathogenesis. Human genital secretions and some sera induced gonococci to serum resistance in vitro. Guinea pig serum was more active than human serum and low molecular weight fractions from it conferred resistance to gonococci in $3 \mathrm{~h}$ at $37^{\circ} \mathrm{C}$. Similar active fractions were obtained from human sera. Now guinea pig serum has been further fractionated for the low molecular weight inducer by membrane filtration, gel filtration on Sephadex G25, high performance liquid chromatography (HPLC) with a Spherisorb ODS reverse phase column, chromatography on Sephadex LH20 and HPLC with a Partisil SCX cation exchange column. The small yield (less than I $\mathrm{mg}$ from $400 \mathrm{ml}$ serum) of highly active material was contaminated with breakdown products from the Partisil SCX column and a mixture of compounds. However, analysis indicated the presence of one or more small glucopeptides containing cysteine, glutamic acid, aspartic acid, threonine, serine, glycine, alanine, valine and lysine. Similar glucopeptides are liberated from fresh human red blood cells in slightly hypertonic saline and samples of them induced gonococci to serum resistance.
\end{abstract}

\section{INTRODUCTION}

The resistance of gonococci to complement-mediated killing, as demonstrated by tests with human serum, is important in the pathogenesis of gonorrhoea (Brooks et al., 1978; Martin et al., 1981). It is of two types. A resistance, retained on subculture in vitro, is exhibited by strains from disseminated gonococcal infections and some strains from urethral pus (Ward et al., 1970; Schoolnik et al., 1976). The second type of resistance is lost phenotypically on subculture in laboratory media and is found in most strains from urethral exudates and from infections of plastic chambers implanted subcutaneously into guinea pigs (Ward et al., 1970; Penn et al., 1976; Rittenberg et al., 1977). This phenotypic type of resistance was induced in vitro by guinea pig chamber fluid and sera, by human genital secretions and, to a lesser extent, by some human sera (Goldner et al., 1979; Veale et al., 1981; Martin et al., 1981, 1982). It was also induced in a defined medium containing $0.1 \%$ bovine serum albumin (BSA) by heat- and acid-labile, low molecular weight fractions from guinea pig and human sera (Veale et al., 1980; Martin et al., 1981). This paper describes further fractionation of the resistance-inducing factor (RIF) from

Abbreviations: EDAX. energy dispersion analysis of X-rays; MQW, 'Milli Q' grade water; $R B C$, red blood cells; RIF, resistance-inducing factor. 
guinea pig serum and the relation of the chemistry of the final product to glycopeptides previously obtained from human red blood cells (RBC).

\section{METHODS}

Neisseria gonorrhoeae. Serum sensitive strain BS4 (agar) was derived and cultured as described previously (Penn et al., 1976, 1977; Goldner et al., 1979). Organisms were stored in liquid nitrogen and used directly after thawing.

Viable counts. These were done as described previously (Veale et al., 1975; Penn ef al., 1976, 1977).

Defined medium. This was prepared as described previously (Veale et al., 1981) and stored at $\mathrm{pH} 4.6$ at $4{ }^{\circ} \mathrm{C}$. Before using it in a mixture with a solution of the resistance inducer (see below), the $\mathrm{pH}$ of which varied according to the sample, the $\mathrm{pH}$ of the defined medium was adjusted to that (6-3-7.0) which preliminary experiments had indicated would yield a final mixture at pH 6.5-6.9 (see below).

Guinea pig serum. Blood was obtained by cardiac puncture from guinea pigs (male, Dunkin-Hartley) under anaesthesia (Sagatal, $0.5 \mathrm{ml}$ per $\mathrm{kg}$ body wt). The blood was allowed to clot at $37^{\circ} \mathrm{C}$ for $\mathrm{I} \mathrm{h}$ and after standing for $24 \mathrm{~h}$ at $4^{\circ} \mathrm{C}$, the serum was removed and stored at $-20^{\circ} \mathrm{C}$ until required for use. After thawing quickly at $37^{\circ} \mathrm{C}$, and inactivating at $56^{\circ} \mathrm{C}$ for $60 \mathrm{~min}$, it was frozen $\left(a t-20^{\circ} \mathrm{C}\right.$ ) and thawed $\left(a t 37^{\circ} \mathrm{C}\right.$ ) twice more before use. The resistance-inducing activity of guinea pig serum was increased (three- to fivefold). like that of human serum (Martin et al. 1981), by the contact with the blood clot for $24 \mathrm{~h}$ at $4^{\circ} \mathrm{C}$ and the subsequent freezings and thawings.

Generation of serum-resistant gonococci. A modification of the method of Veale et al. (1981) was used. The medium consisted of known concentrations of guinea pig serum or its fraction (filtered through $0.22 \mu \mathrm{m}$ Millipore membranes) in defined medium at pH 6.5-6.9. Samples $(100 \mu \mathrm{l})$ were placed in the wells of micro-titre plates (Flow Laboratories). In experiments with low molecular weight fractions, $0.1 \%$ bovine serum albumin (BSA) was added to maintain gonoccal viability by replacing $5 \mu$ l of the defined medium with $5 \mu l$ of $2 \%(w / v)$ BSA solution. To each well, $10 \mu \mathrm{l}$ of a suspension of BS4 (agar) organisms $\left(1-4 \times 10^{5} \mathrm{c} . \mathrm{f} . \mathrm{u} . \mathrm{ml}^{-1}\right.$ ) was added and, after incubating for $3 \mathrm{~h}$ at $37^{\circ} \mathrm{C}$, the resistance of the gonococci to killing by human serum was measured as described below. During the incubation, the concentration of gonococci $\left(1-4 \times 10^{4}\right.$ c.f.u. $\left.\mathrm{ml}^{-1}\right)$ did not increase more than twofold.

Test for resistance to killing by fresh human serum. The test of Veale et al. (1981) was used. Resistance to killing was calculated as the number of c.f.u. recovered, after incubation for $40 \mathrm{~min}$ at $37^{\circ} \mathrm{C}$ with fresh human serum as a percentage of the number recovered after incubation with heat-inactivated $\left(56^{\circ} \mathrm{C}, 30 \mathrm{~min}\right)$ human serum. The bactericidal activity of the fresh human serum (in $40 \mathrm{~min}$ at $37^{\circ} \mathrm{C}$ ) was determined in each experiment against strain BS4 (agar) with and without the amount of inducer that would have been carried over from the generation of resistant organisms (see above).

An approximate assay of the RIF. The position of RIF in elution profiles from fractionation procedures was located by examining individual fractions, without dilution or concentration, for ability to convert strain BS4 (agar) to resistance in the standard test (see above). Then, an indication of the recovery of RIF in pooled fractions was obtained by the following approximate assay. After preliminary experiments to indicate appropriate concentrations, three threefold dilutions of serum or serum fractions were used to induce serum resistance to different degrees as determined in the standard assay. At appropriate concentrations, a three- to ninefold dilution of RIF reduced serum resistance from $80-100 \%$ to $2-10 \%$ (observations on $>30$ samples). The concentration of the particular fraction converting $50 \%$ of the gonococci to resistance was derived from the percentage serum resistance induced above and below $50 \%$ by two of the three dilutions examined, assuming direct proportionality between concentration and resistance-inducing activity. Repeat assays on three separate batches of guinea pig serum gave $50 \%$ conversion concentrations of 8 and $7 \%(v / v) ; 14$ and $11 \%(v / v)$; and 16,18 and $14 \%(v / v)$. Similarly, repeat assays on two batches of a YM-5 ultrafiltrate of the serum (see later) gave $50 \%$ conversion concentrations of 26,24 and $24 \%(v / v)$ and 28 and $30 \%(v / v)$.

For estimates of the recovery of RIF in the fractionation process described below, the $50 \%$ conversion concentration $(\%, v / v)$ for each pooled active fraction was calculated with respect to a solution of the same volume as that of the original serum. This procedure was adopted rather than relating activity to some arbitrarily chosen parameter, e.g. protein content, because of the unknown nature of RIF. Only in the final stages of the purification procedure was $50 \%$ conversion activity related to dry weight of fractions.

At each stage of the fractionation, the inactive individual fractions were pooled, concentrated and examined in the biological test at concentrations equivalent to the highest of the three concentrations used in the assay of the pooled active fraction (or lower if this concentration proved toxic to the test gonococci as did fractions from the Sephadex G2S columns). If this concentration did not convert $50 \%$ of the gonococci to resistance then absence of detectable activity was recorded.

Ultrafiltration of serum. Initially, batches of pooled serum (150-200 ml) were filtered in $50 \mathrm{ml}$ aliquots on XM-50 Diaflo membranes (nominal cut off 50000 daltons) at $4^{\circ} \mathrm{C}$ in a stirred Amicon cell (model 52 ) under nitrogen pressure ( $50 \mathrm{lbf}$ in $\left.^{-2} ; 345 \mathrm{kPa}\right)$. The thick retentate $(15-30 \%$ of the original serum volume) was washed three times with $50 \mathrm{ml}$ water. The filtrate (70-85\% of the original volume) was filtered through one PM-10 Diaflo membrane (nominal cut off 10000 daltons), then through a YM-5 Diaflo membrane (nominal cut off 5000 daltons) and finally 
through a UM-2 Diaflo membrane (nominal cut of 1000 daltons). The retentates from the PM-10, YM-5 and UM2 membranes (volumes $5-10^{\circ}$ of the original serum) were washed twice with equal volumes of water. All the fil. trates and washed retentates were assayed for RIF. No attempt was made to recover and assay the RIF in the washings of the retentates. When partial retention of RIF by the UM-2 membrane became apparent, the YM-5 filtrate was freeze dried, suspended in water (volume equivalent to that of the original serum) and filtered through Whatman GF/C paper before RIF assay.

After the initial ultrafiltration experiments, YM-5 filtrates were prepared for further fractionation as follows. Pooled serum $(100-110 \mathrm{ml})$ was filtered in equal aliquots through XM- 50 membranes in three cells. The thick retentate (15-30\% of the original serum volume) on each membrane was washed with $30-35 \mathrm{ml}$ water. The pooled filtrates and washings were filtered through one YM-5 membrane, freeze dried, dissolved in $5 \mathrm{ml}$ ' Milli Q' grade water (MQW) and filtered through Whatman GF/C paper and then through a $0.22 \mu \mathrm{m}$ Millipore membrane before RIF assay

In subsequent fractionation procedures, water was the preferred eluant because it allowed easy testing of fractions for biological activity either directly or after freeze drying.

Gel filtration on coarse and superfine Sephadex G25. The YM-5 filtrate ( $5 \mathrm{ml}$ : from $100-110 \mathrm{ml}$ serum) was applied to a column ( $25 \times 450 \mathrm{~mm}$ ) of Sephadex G25 coarse gel (Pharmacia) which was equilibrated and eluted with MQW. The elutate was monitored at $279 \mathrm{~nm}$ and fractions $(5 \mathrm{ml})$ were kept at $-20^{\circ} \mathrm{C}$ until tested for RIF. Active fractions were pooled and freeze dried. Then, (wo batches (from $200-220 \mathrm{ml}$ serum) were dissolved in 2-3 ml MQW, and applied to a column (15 $\times 850 \mathrm{~mm})$ of Sephadex G25 superfine gel equilibrated with MQW. The column was eluted, individual fractions were tested, and the pooled active material was freeze dried as before.

High pressure liquid chromatography (HPLC): Spherisorb ODS (rererse phase) column. Two batches of material prepared by gel filtration (from $400-440 \mathrm{ml}$ serum) were dissolved in MQW ( $2 \mathrm{ml}$ ), filtered through a $0.22 \mu \mathrm{m} \mathrm{Mil-}$ lipore membrane, sampled for RIF assay and fractionated on a Spherisorb ODS (reverse phase) column (7.8 $\times$ $250 \mathrm{~mm}$ ) with MQW as the medium, at a fow rate of $2 \mathrm{ml} \mathrm{min}^{-1}$ and a pressure of $2500 \mathrm{lbF}^{-2} \mathrm{n}^{-2}(17.24 \mathrm{MPa})$. Eluates were monitored at $279 \mathrm{~nm}$. Fractions were kept at $-20^{\circ} \mathrm{C}$, monitored for RIF, pooled and freeze dried.

Fractionation on Sephadex LH20 column. Material from the Spherisorb ODS column (from $400-440 \mathrm{ml}$ serum) was dissolved in MQW ( $2 \mathrm{ml}$ ), filtered through a $22 \mu \mathrm{m}$ Millipore membrane, sampled for RIF assay and applied to a column ( $15 \times 1500 \mathrm{~mm}$ ) of Sephadex LH20 gel. The column was eluted with MQW and the fractions ( $5 \mathrm{ml}$ ) treated as for the previous column.

HPLC: Partisil SCX cation exchange column. The RIF is acid-labile (Veale et al., 1980) but preliminary experiments showed that at $\mathrm{pH} 4.5$ it was stable for $4 \mathrm{~h}$ at room temperature and for $18 \mathrm{~h}$ at $4{ }^{\circ} \mathrm{C}$. The material from the Sephadex LH20 gel column (from $400-440 \mathrm{ml}$ serum) was dissolved in MQW (2 ml), filtered through a $0.22 \mu \mathrm{m}$ Millipore membrane, sampled for RIF assay and adjusted at $4{ }^{\circ} \mathrm{C}$ to $\mathrm{pH} 4.5$ with $5 \mathrm{M}-\mathrm{HCl}$. Aliquots $(150-250 \mu \mathrm{l})$ were applied to a Partisil SCX column (7.8 $\times 250 \mathrm{~mm}$ ), equilibrated at room temperature with 0.0I M-NH $\mathrm{NH}_{2} \mathrm{PO}_{4}$ (at pH 4.5, adjusted with ammonia solution) and separated by HPLC using a flow rate of $1.5 \mathrm{ml} \mathrm{min} \mathrm{m}^{-1}$ and pressure of $1000 \mathrm{lbf}^{-2}\left(6.89 \mathrm{MPa}\right.$ ). Each separation took about $30 \mathrm{~min}$. Eluates (in $0.01 \mathrm{M}-\mathrm{NH}_{4} \mathrm{H}_{2} \mathrm{PO}_{4}$ al $\mathrm{pH} 4.5$ ) were monitored at $206 \mathrm{~nm}$ and fractions were stored on ice. Corresponding fractions from three aliquots were collected together and adjusted to pH 7.0 with ammonia solution. When fractions from all aliquots had been collected, corresponding fractions were pooled and stored at $-20^{\circ} \mathrm{C}$ for $\mathrm{RIF}$ assay. The active pooled fraction was concentrated and freed from ammonium phosphate by ultrafiltration on a single YC -05 Diaflo membrane (nominal cut off 500 daltons), and washing twice with $40 \mathrm{ml}$ and three times with $15 \mathrm{ml}$ water (HPLC grade: Fisons). It was freeze dried, weighed and dissolved in $2 \mathrm{ml}$ water (HPLC grade). After removing any insoluble material (which was dried and weighed), the soluble material was stored at $-20^{\circ} \mathrm{C}$ for chemical analysis and RIF assay.

Chemical analysis. Amino acid analysis was carried out on a Locarte analyser (Locarte Ltd, London, UK) after hydrolysis of the preparation $(20-40 \mu \mathrm{g})$ with $6 \mathrm{~m}-\mathrm{HCl}$ under vacuum for $24 \mathrm{~h}$ at $110^{\circ} \mathrm{C}$. Experiments with equivalent quantities of cysteine and synthetic peptides containing $\mathbf{N}$-terminal cysteine showed that cysteine was not detected either as itself or as cystine after this procedure. Samples were also analysed for hexosamine on a Locarte analyser after hydrolysis of the preparation $(20-40 \mu \mathrm{g})$ in $6 \mathrm{x}-\mathrm{HCl}$ at $100^{\circ} \mathrm{C}$ for $6 \mathrm{~h}$. Neutral sugars were detected by ion exchange chromatography of their borate complexes (Kennedy \& Fox, 1980) after hydrolysis of the preparation $(20-40 \mu \mathrm{g})$ by $2 \mathrm{M}$-trifluoroacetic acid for $6 \mathrm{~h}$ at $100^{\circ} \mathrm{C}$

After the biological activity of the glucopeptides obtained by S. A. Kaaba \& J. B. Weiss (personal communication) from human RBC was known (see Results), and the fact that cysteine had not been detected by them in these glucopeptides after acid hydrolysis $\left(6 \mathrm{M} \cdot \mathrm{HCl}, 16 \mathrm{~h}, 105^{\circ} \mathrm{C}\right) . \mathrm{N}$-terminal cysteine was estimated in our material by an adaptation of their method. The final material from the Partisil SCX column (200 $\mu \mathrm{l}$; approx. $100 \mu \mathrm{g}$ ) was incubated with 20 units of leucine amino-peptidase (EC 3.4.1.1: Sigma) in $800 \mu \mathrm{l} 0.1 \mathrm{~m}$ $\mathrm{NaHCO}_{3}$ /acetic acid bufier ( $\mathrm{pH} 7.5$ ) for $15 \mathrm{~min}$ at $37^{\circ} \mathrm{C}$. The subsequent steps used by $\mathrm{S}$. A. Kaaba \& J. B. Weiss (personal communication) allowed only qualitative detection of cysteine by paper chromatography after acid hydrolysis. In order to quantify the terminal amino acid, we used the following modification. The reaction mixture was hydrolysed in $1 \mathrm{M}-\mathrm{HCl}$ for $1 \mathrm{~h}$ at $100^{\circ} \mathrm{C}$ under nitrogen. dried in racuo and dissolved in $10 \%$ formic acid before 
Table 1. Resistance-inducing activity of fractions from ultrafiltration of guinea pig serum

The figures are representative of the results from four similar experiments with different batches of starting material.

\begin{tabular}{|c|c|c|c|}
\hline Filter* & Fraction & $\begin{array}{l}\text { Approx. fraction } \\
\text { volume } \\
\text { (percentage of } \\
\text { original volume } \\
\text { of serum) }\end{array}$ & RIF activity \\
\hline XM-50 & $\begin{array}{l}\text { Serum } \\
\text { Retentate (washed) } \ddagger \\
\text { Filtrate }\end{array}$ & $\begin{array}{c}100 \\
15-30 \\
70-85\end{array}$ & $\begin{array}{r}14 \\
>45 \\
30\end{array}$ \\
\hline PM-10 & $\begin{array}{l}\text { Retentate (washed) } \ddagger \\
\text { Filtrate }\end{array}$ & $\begin{array}{c}5 \\
65 \cdot 80\end{array}$ & $\begin{array}{r}>45 \\
29\end{array}$ \\
\hline YM-5 & $\begin{array}{l}\text { Retentate (washed) } \ddagger \\
\text { Filtrate } \\
\text { Filtrate (freeze dried) }\end{array}$ & ${ }_{60-75}^{5}$ & $\begin{array}{r}>45 \\
28 \\
26\end{array}$ \\
\hline UM-2 & $\begin{array}{l}\text { Retentate } \\
\text { Filtrate }\end{array}$ & $\begin{array}{r}5-15 \\
55-60\end{array}$ & $\begin{array}{r}40 \\
>45\end{array}$ \\
\hline
\end{tabular}

- The characteristics of the filters are described in Methods; the PM-10 filter received the filtrate from the XM50 filter and so on through the filters.

† Concentration $(\%, \mathrm{v} / \mathrm{v})$ inducing $50 \%$ resistance in the standard inoculum of strain BS4 (agar). Before assay, all fractions were diluted to the original volume of serum.

$\ddagger$ No attempt was made to recover resistance-inducing activity from the 2-3 washings (see Methods).

analysis on a Locarte amino acid analyser as described above. After appropriate preliminary experiments the following two control experiments were done in parallel with the estimation of cysteine in the fractions from the Partisil SCX column. Cysteine (496 nmol in the first experiment: $330 \mathrm{nmol}$ in the second experiment) was treated as described for the material from the Partisil SCX column; analysis of the product on the Locarte analyser showed no evidence for the presence of cysteine but cystine ( $76 \mathrm{nmol}$ in the first experiment; $40 \mathrm{nmol}$ in the second experiment) was present. Since 496 and 330 nmol cysteine would convert to 248 and 165 nmol cystine, respectively, the recovery of cysteine as cystine in the control experiments was $31 \%$ and $24 \%$. Controls using the leucine aminopeptidase alone produced a background of some amino acids but cysteine and cystine were absent and the background did not interfere with the estimation of cystine in experimental samples. As for the cysteine controls, the material from the Partisil SCX column showed no evidence for the presence of cysteine but cystine was detected at the levels reported in Results.

Silica, sulphur and other elements were detected using electron microscopy and energy dispersion analysis of $\mathrm{X}$. rays (EDAX) on known amounts (0.1 $\mu$ l of a solution containing $\left.0.6-0.8 \mathrm{mg} \mathrm{m}^{-1}\right)$ of purified RIF dried on Formvar-coated grids.

Samples of glucopeptides from human RBC. Dr J. B. Weiss (Department of Biochemistry, University of Manchester, UK) kindly donated two samples of different glucopeptides that had been released from intact human RBC by mild osmotic shock and purified by fractionation on Sephadex $\mathrm{G} 15$ and Biogel $P_{2}$ columns. The samples (6- $7 \mathrm{mg}$. containing $97 \% \mathrm{NaCl}$ ) had been obtained from approximately $200 \mathrm{ml}$ fresh human blood, freeze dried from saline solution and stored for 4 years under nitrogen. The glucopeptides (SIa and SIb) contained glucose molecules ( 2 and 4, respectively) linked to $\mathrm{N}$-terminal cysteine and different proportions of serine, glutamic acid, glycine and alanine, with traces of aspartic acid and threonine being present in the preparations (S. A. Kaaba \& J. B. Weiss, personal communication).

\section{RESULTS}

The $50 \%$ conversion concentrations in the assay of RIF that are quoted for the fractions described below were calculated with respect to a solution of the fraction of the same volume as that of the serum from which it was obtained.

\section{Ultrafiltration of guinea pig serum}

The RIF passed the XM-50, PM-10 and YM-5 membranes (Table 1), indicating that its molecular weight was less than 5000 daltons. Although only partially retained by UM-2 filters (nominal cut off 1000 daltons), it was freeze dried without loss of activity, allowing full recovery from the YM-5 filtrate (Table I). Between 15 and $30 \%$ of the RIF was lost in the viscous reten- 
tate on the XM-50 filter. After washing three times, resistance inducing activity could not be detected in the high molecular weight retentate at the concentration examined (Table 1) although it may have had a weak inherent activity. Recovery of RIF in the washings was not attempted. There were further small inevitable losses of volume in retentates as the filtrate from the XM-50 membrane passed through other filters. The $50 \%$ conversion concentrations for the XM-50, PM10 and YM-5 filtrates $(30,29$ and $28 \%, \mathrm{v} / \mathrm{v}$, respectively) indicated that there was little loss of RIF after the XM-50 filter and that about half of the RIF of the original serum $(50 \%$ conversion concentration; $14 \%, v / v)$ was recovered. This was satisfactory in view of the $25-40 \%$ loss of volumes (and, therefore, RIF because it was not recovered from the washings) on the membranes.

In subsequent preparations of RIF, filtration through PM-10 membranes was omitted and only the original serum and the final freeze dried filtrates were assayed. In five typical experiments, the $50 \%$ conversion concentrations of sera and their YM-5 filtrates were 10, 5, 8, 13 and $4 \%(\mathrm{v} / \mathrm{v})$ and $37,10,15,11$ and $8 \%(\mathrm{v} / \mathrm{v})$, respectively. Thus, about half of the original RIF activity was recovered.

The fact that the biological activity was only partially retained on the Diaflo UM-2 membrane (see Table 1) indicated a molecular weight for the RIF of not much greater than 1000 daltons. The results of the following experiment showed that some RIF did pass this filter but was retained by a Diaflo YC-05 membrane (nominal cut off 500 daltons). A solution $(5 \mathrm{ml}$ ) of the freeze dried YM-5 filtrate from guinea pig serum (see above) was filtered on a UM-2 membrane and the retentate was washed $(2 \times 15 \mathrm{ml}$ water). The retentate (approx. $2 \mathrm{ml})$ was diluted to $5 \mathrm{ml}$ for biological assay. The filtrate and washings were filtered through a YC-05 membrane and the retentate (approx. $2 \mathrm{ml}$ ) and a solution of the freeze dried filtrate (approx. $2 \mathrm{ml}$ ) were assayed biologically after diluting to $5 \mathrm{ml}$. In the biological assay for RIF, the filtrate from the YC-05 membrane was inactive and the concentrations of the original YM-5 filtrate, the UM-2 retentate and the YC-05 retentate that converted $50 \%$ of the gonococci to resistance were $(\%, v / v) 4 \cdot 2,4.4$ and 36, respectively, in one experiment and 2.0,3.0 and 40 in another. Thus, about $10 \%$ of the RIF passed the UM-2 membrane and was retained on the YC-05 membrane. The integrity of the filter was checked after the experiment by filtering an aqueous extract of RBC.

\section{Gel filtration}

The elution profiles of the YM-5 filtrate on Sephadex G25 (coarse) and then on G25 (superfine) are shown in Fig. 1 ( $a$ and $b$, respectively). Clearly, much material was removed from the RIF and after pooling of the fractions and concentration biological activity was not detected. In three representative experiments, about half of the RIF activity in the YM-5 filtrate was recovered from the Sephadex G25 (superfine) column (Table 2).

\section{HPLC on Spherisorb ODS}

The elution profile of the material from gel filtration when submitted to partition chromatography on HPLC with a Spherisorb ODS (reverse phase) column is shown in Fig. 2 (a). There were two absorption peaks : the first consisted of an asymmetric peak which contained all the RIF activity. The second peak appeared to consist of two overlapping components, and when the corresponding fractions were pooled and concentrated, no RIF activity could be detected. Other material absorbing at $279 \mathrm{~nm}$ remained on the column and was recovered by elution with methanol (which in preliminary experiments was shown not to inactivate RIF); after evaporating the methanol and dissolving the residue in water, biological activity was not detected. In four experiments, more than half of the RIF in the material from gel filtration was recovered from the Spherisorb column (Table 2).

\section{Chromatography on Sephadex LH20 gel}

The elution profile of the material from the Spherisorb ODS column on Sephadex LH20 is shown in Fig. 2(b). Again, some UV-absorbing material was eluted after the fractions containing RIF activity. When fractions containing this later material were pooled and con- 

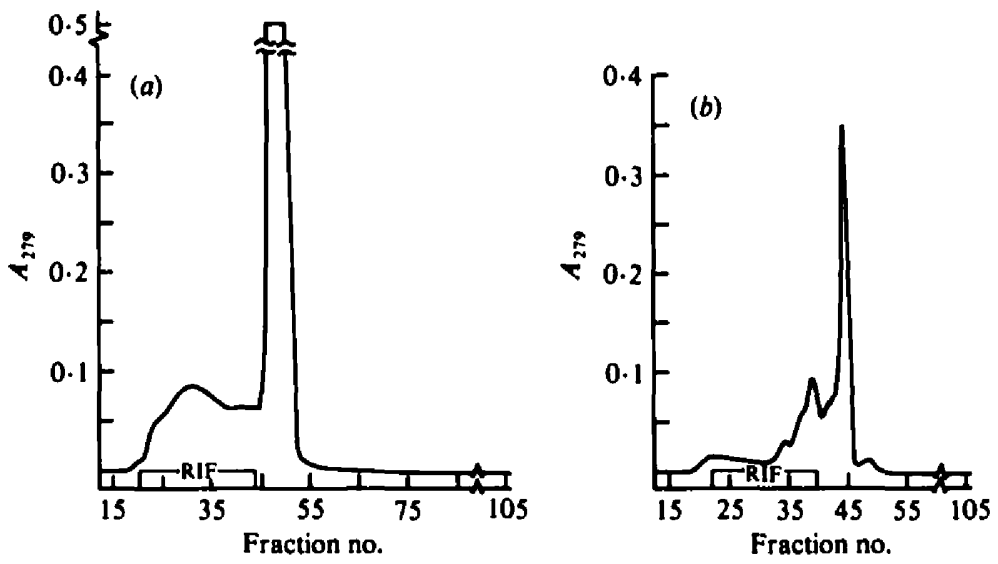

Fig. 1. Fractionation of RIF by gel filtration. Elution profiles ( $279 \mathrm{~nm}$ ) of YM-5 filtrate on (a) Sephadex G25 coarse and then on (b) Sephadex G25 superfine. The active fractions are indicated by $r$ RIF_. See text for the total activity recovered.

Table 2. Resistance-inducing activities of fractions at successive stages in the fractionation of $R I F$

Stage in fractionation

\begin{tabular}{rrrrrrrrrrrrrr} 
& & \multicolumn{10}{c}{ RIF activity* } \\
10 & 5 & 13 & 8 & 4 & & & & & & & & \\
37 & 10 & 11 & 15 & 8 & 27 & & & & & & & \\
& & & 15 & 15 & 29 & & & & & & & \\
& & 37 & 22 & 28 & 15 & 10 & 14 & & & & \\
& & & & 35 & 21 & 16 & 14 & 20 & & & \\
& & & & 100 & & 62 & 31 & 45 & 50 & 160 & 180 \\
& & & & 140 & & & & & 90 & 180 & 180
\end{tabular}

Original serum

YM-5 filtrate

G25 Coarse

G25 Fine

Spherisorb ODS

Sephadex LH2O

140

$\begin{array}{lll}90 & 180 & 180\end{array}$

Partisil SCX

- Concentration $(\%, v / v)$ of active fraction inducing $50 \%$ resistance in the standard inoculum of strain BS4 (agar). All concentrations are quoted in relation to the volume of the original serum sample. The results vertically below one another apply to the same batch of material.

centrated, no RIF activity was detected. In four experiments, however, only about one-third of the RIF was recovered after this stage of fractionation (Table 2).

Chemical analyses of three samples of material at this stage showed peptide moieties were present containing up to 12 amino acids and carbohydrate moieties containing glucose, galactose, mannose and other sugars.

\section{HPLC on Partisil SCX cation exchange column}

The elution profile of the material from the Sephadex LH20 column on the HPLC Partisil cation exchange column is shown in Fig. 2(c). In four experiments, the fractions eluted after the RIF peaks, were pooled and concentrated and biological activity was not detected. More than half of the RIF in the material from the Sephadex LH20 column was recovered from the HPLC Partisil SCX column (after concentration and washing on a YC-05 membrane and freeze drying ; Table 2).

Analysis of the active material from the Partisil SCX cation exchange column

The freeze dried material was analysed to provide an indication of the nature of the RIF. The results on three representative batches (Table 3) show many similar features. First, their dry weights (1-2 mg from $400 \mathrm{ml}$ serum) and the amounts needed to convert $50 \%$ of gonococci in resistance in the standard test (less than $1 \mu \mathrm{g}$ ) were similar. Second, they all contained aspartic 


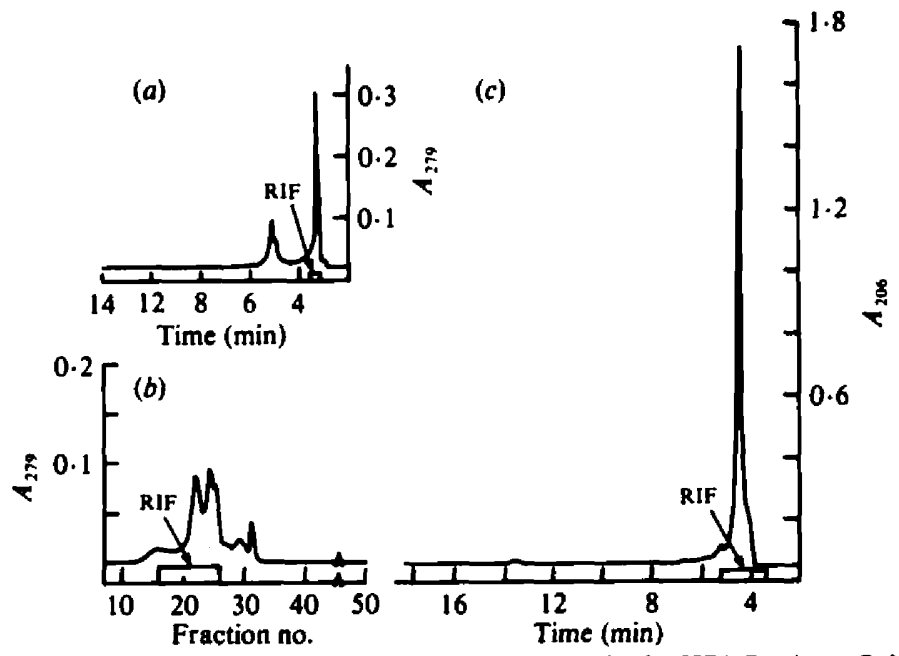

Fig. 2. Elution profiles during progressive fractionation of RIF by (a) HPLC using a Spherisorb ODS column (279 nm), (b) a Sephadex LH20 column (279 nm), and (c) HPLC at pH 4.5 using a Partisil SCX cation exchange column $(206 \mathrm{~nm})$. The fractions containing RIF are indicated by 7 See text for activity recovered at each stage.

Table 3. Analysis of purified preparations of RIF from the HPLC Partisil SCX column (benzenesulphonic acid groups bonded to a silica gel)

These analyses of three batches of material were representative of those of seven batches.

\section{Analysis}

Dry weight from $400 \mathrm{ml}$ serum $(\mathrm{mg})$

Amount inducing resistance in $50 \%$ of gonococci in the assay $(\mu \mathrm{g})$

Amino acid (nmol $\mathbf{m g}^{-1}$ ):

Aspartic acid

Threonine

Serine

Glutamic acid

Glycine

Alanine

Valine

Isoleucine

Leucine

Phenylalanine

Lysine

Others

N-terminal cysteine*

Glucosamine

Neutral sugar (nmol $\mathbf{m g}^{-1}$ ):

Glucose

Otherst

Elements by EDAX $\ddagger$

$\mathbf{S i}$

$\mathbf{S}$

$\mathbf{K}$

$\mathbf{P}$
Preparation:

\begin{tabular}{ccc}
\hline 1 & 2 & 3 \\
$1 \cdot 7$ & $1 \cdot 6$ & $1 \cdot 3$ \\
0.8 & $0 \cdot 7$ & $0 \cdot 4$ \\
& & \\
68 & 63 & 92 \\
33 & 38 & 48 \\
33 & 63 & 60 \\
82 & 100 & 461 \\
64 & 125 & 108 \\
35 & 63 & 48 \\
19 & 38 & 49 \\
nil & 13 & nil \\
nil & 38 & 19 \\
nil & 25 & nil \\
24 & 50 & 32 \\
nil & nil & nil \\
60 & 80 & 140 \\
nil & nil & nil \\
& & \\
210 & 280 & 240 \\
nil & nil & nil \\
& & \\
+++ & ++++ & ++++ \\
+++ & +++ & ++++ \\
++ & ++ & + \\
++ & \pm & \pm
\end{tabular}

- Determined after treatment with leucine aminopeptidase as described in Methods.

† In analysis of some preparations a small broad elution band was seen probably representing breakdown products, but specific peaks other than that due to glucose were not seen.

$\ddagger$ Accurate analysis was impossible because the dried droplets of RIF solution were heterogeneous in content of elements in different areas. The scoring ++++ to + gives an impression of the average level of detection of elements in four to six different areas for each sample. 
acid, serine, threonine, glutamic acid, glycine, alanine, valine and lysine, with the amounts of aspartic acid, glutamic acid and glycine being consistently high. Third, glucosamine was absent from all preparations. Fourth, glucose was the only neutral sugar present in all preparations and at similar levels.

The total contents of amino acids and glucose accounted for less than $15 \%$ of the weight of the preparations from the Partisil SCX column. EDAX showed that all RIF preparations contained substantial quantities of both silica and sulphur and small amounts of potassium. The SCX column is a silica gel coated with benzenesulphonic acid groups. Hence, the large amounts of silicon and sulphur make it reasonable to assume, in the absence of evidence for appreciable quantities of other residues, organic or inorganic, that breakdown products from the SCX column constituted most, if not all, of the remaining $85 \%$ of the RIF preparations. The source of the potassium is unknown but it may have been derived from potassium silicate possibly used in preparing the column.

\section{Examination of the glucopeptides from human RBC for ability to induce gonococci to serum resistance}

The similarity between the analysis of the resistance-inducing material from guinea pig serum (Table 3) and that of glucopeptides obtained from human RBC (Weiss et al., 1971; S. A. Kaaba \& J. B. Weiss, personal communication) prompted an examination of the latter for biological activity. Two samples of glucopeptides (0.25 and $0.23 \mathrm{mg}$ SIa and SIb, respectively) were dissolved in $1 \mathrm{ml}$ water. Different concentrations were tested for ability to induce strain BS4 (agar) to serum resistance in the standard test. The amounts inducing $50 \%$ of the gonococci to resistance were 12-24 $\mu \mathrm{g}$ and 14-28 $\mu \mathrm{g}$ for SIa and SIb, respectively. After being heated at $75^{\circ} \mathrm{C}$ for $1 \mathrm{~h}$ at neutral $\mathrm{pH}$ or incubated at $37^{\circ} \mathrm{C}$ for $\mathrm{I} \mathrm{h}$ at pH 2, $12 \mu \mathrm{g}$ SIa and $14 \mu \mathrm{g}$ SIb were unable to induce $5 \%$ of the gonococci to resistance.

\section{Examination of the resistance inducing material from guinea pig serum for $\mathbf{N}$-terminal cysteine}

When examined for $\mathbf{N}$-terminal cysteine residues by a modification of the method of $\mathbf{S}$. $\mathbf{A}$. Kaaba \& J. B. Weiss (personal communication) which detected cysteine as cystine (see Methods), preparations 1, 2 and 3 obtained from the Partisil SCX column (Table 3) yielded 8, 12 and $20 \mathrm{nmol}$ cystine $\mathrm{mg}^{-1}$, respectively. On the assumption that the recovery of cysteine as cystine from these preparations is similar to that (24-31\%) obtained in control experiments with cysteine (see Methods), these results indicate contents of approx. 60,80 and $140 \mathrm{nmol}$ cysteine, respectively, in preparations 1,2 and 3.

\section{DISCUSSION}

Fractionation of guinea pig serum for the RIF has been a difficult task because of its low concentration. Nevertheless, considerable progress has been achieved by using a multi-stage process in which biological activity was followed by an approximate assay for RIF. In most stages of the fractionation, half or more than half of the RIF was recovered with the exception of the separation on Sephadex LH20 gel. The overall recovery of resistance-inducing activity in the purified material was about $4 \%$ of that in the original serum. It was unfortunate that breakdown products of the Partisil SCX column contaminated the final material. This was not suspected until it became evident for several batches that their sugar and amino acid analyses accounted for less than $15 \%$ of their weight and that there was no evidence of appreciable amounts of other residues such as purines, pyrimidines and lipids. The availability of EDAX allowed elemental analysis on small quantities of material and this revealed substantial amounts of silica and sulphur clearly derived from the SCX column which is a silica gel coated with benzenesulphonic acid groups. Accurate measurement of the amount of breakdown products was not possible (see footnote to Table 2), but it is reasonable to assume that they made up $85 \%$ or more of the final material. 
The final material was highly active and less than $1 \mu \mathrm{g}$ induced serum resistance in $50 \%$ of the gonococci used in the standard assay. The elution profile of the material from the Partisil SCX column (Fig. Ic) and the chemical analysis of three batches (Table 2) showed that impurities remained and that more than one glycopeptide was present. However, the striking features of all batches were: (1) the presence of threonine, serine, alanine, valine and lysine and relatively high contents of aspartic acid, glutamic acid and glycine; (2) glucose as the only identifiable neutral sugar; and (3) the absence of hexosamine. This indicated that one or more glucopeptides were present. The ultrafiltration data indicated a molecular weight for RIF of not far above 1000 daltons because about $10 \%$ of it passed a UM-2 membrane which has a nominal cut off of 1000 daltons. Hence, the active material may not contain all the eight amino acids listed above.

Weiss et al. (1971) described a low molecular weight glycopeptide containing triglucosyl cysteine linked to six other amino acids; it was liberated from intact human RBC by mild osmotic shock. Later work (S. A. Kaaba \& J. B. Weiss, personal communication) has shown it to be one of a family of similar peptides containing up to four glucose molecules and $\mathrm{N}$-terminally linked cysteine, serine, glutamic acid, glycine and alanine; small amounts of aspartic acid and threonine were present in most preparations. Before we were aware of Dr Weiss's work with intact RBC, the possibility of the low molecular weight RIF being one or more of such glucopeptides originating from $R B C$ was supported by our finding of far more resistance-inducing activity in lysates of human and guinea pig RBC than in the corresponding plasma or sera (Patel et al., 1984). This possibility was further strengthened by finding evidence of $\mathrm{N}$-terminal cysteine residues in the guinea pig-derived material and demonstrating that two glucopeptides from human RBC possessed resistance-inducing activity.

Cysteine was not detected in the original amino acid analysis of the guinea pig-derived material from the Partisil SCX column after hydrolysis with $6 \mathrm{M}-\mathrm{HCl}$. However, when the material was examined for $\mathrm{N}$-terminal cysteine by a modification of the method of $\mathrm{S}$. A. Kaaba \& J. B. Weiss (personal communication), all three batches yielded cystine which indicated $\mathbf{N}$-terminal cysteine groups (see Methods). Furthermore, after the results were corrected by comparison with those of relevant control experiments, the contents of cysteine indicated (approx. 60, 80 and $140 \mathrm{nmol} \mathrm{mg}^{-1}$ for the three preparations $\mathrm{l}, 2$ and 3) were similar to those for some of the other amino acids (Table 3 ).

Two glucopeptides (Sla and SIb) had resistance-inducing activity in the standard test but at a lower level than in the guinea pig-derived material although, as for the latter, the activity was heat- and acid-labile. There are several possible reasons for the lower activity. There may be several active glucopeptides with a spectrum of activity and the less active ones may be in human RBC. In this respect, there was less resistance-inducing activity in lower molecular weight ultrafiltrates from human sera and RBC lysates than from corresponding guinea pig materials (Martin et al., 1981; Patel et al., 1984). On the other hand, glucopeptides SIa and SIb may have lost activity during their 4 year storage. It is known (J. B. Weiss, personal communiciation) that on storage thiazolidine formation can occur between cysteine and sugar moieties. Also, it is uncertain whether the differences in activities between the guinea pig- and human-derived material may reflect the presence of different ratios of the same components in each species. Purification of the low molecular weight RIF from human and guinea pig blood will show which is correct.

The evidence presented raises the possibility that the minute amounts of low molecular weight RIF in guinea pig serum and similar material in some human sera (Martin et al., 1981) may be glycopeptides possibly derived from RBC membranes which contain glucosyl cysteine and up to six to eight other amino acids. Whether the resistance-inducing activity of urogenital secretions might also be due to such glucopeptides and whether the high molecular weight inducing factor found in human sera and RBC (Martin et al., 1981; Patel et al., 1984) is connected with them, are matters for further research.

Our thanks are due to Mrs C. Sammons for excellent technical assistance. We are also indebted to Professor $\mathbf{M}$. Loretto and Dr A. Nicholls, Department of Metallurgy and Materials, University of Birmingham, UK, for detection of $\mathrm{Si}, \mathrm{S}$ and other elements. 


\section{REFERENCES}

Brooks, G. F., Gotschlich, E. C., Holmes, K. K., SAWYER, W. D. \& YOUNG, F. E. (1978). Immunobiology of Neisseria gonorrhoeae. Washington. DC: American Society for Microbiology.

Goldner, M., Penn, C. W., Sanyal, S. C., Veale, D. R. \& Sum,, H. (1979). Phenotypically determined resistance of Neisseria gonorrhoeae to normal human serum: environmental factors in subcutaneous chambers in guinea pigs. Journal of General Microbiology 114, 169-177.

KenNEDY, J. F. Fox, J. E. (1980). Fully automatic ion-exchange chromatographic analysis of neutral monosaccharides and oligosaccharides. Methods in Carbohydrate Chemistry 8, 3-12.

Martin, P. M. V., Patel, P. V., Parsons, N. J. a SMITh, H. (1981). Induction of phenotypically determined resistance of Neisseria gonorrhoeae to human serum by factors in human serum. Journal of General Microbiology 127, 213-217.

Martin, P. M. V., Patel, P. V., Parsons, N. J. \& SMITH, H. (1982). Induction in gonococci of phenotypic resistance to killing by human serum by human genital secretions. British Journal of Venereal Diseases 58. 363-365.

Patel, P. V., Martin, P. M. V., Goldner, M., Parsons, N. J. \& Surth, H. (1984). Red blood cells, a source of factors which induce Neisseria gonorrhoeae to resistance to complement-mediated killing by human sera. Journal of General Microbiology 130 , 2767-2770.

Penn, C. W., Sen, D., Veale, D. R., Parsons, N. J., SMITH, H. \& WITT, K. (1976). Morphological, biological and antigenic properties of Neisseria gonorrhoeae adapted to growth in guinea pig subcutaneous chambers. Joumal of General Microbiology 97 , 35-43.

Penn, C. W., Veale, D. R. \& Smith, H. (1977).
Selection from gonococci grown in vitro of a colony type with some virulence properties of organisms adapted in tivo. Joumal of General Microbiology 100. 147-158.

Rittendero, S. C., Penn, C. W., Parsons, N. J., Veale, D. R. Smrth, H. (1977). Phenotypic changes in the resistance of Neisseria gonorrhoeae to killing by normal human serum. Journal of General Microbiology 103, 69-75.

SChOOLnix, G. K., BuchaNaN, T. M. \& Holmes, K. K. (1976). Gonococci causing disseminated gonococcal infection are more resistant to the bactericidal action of normal human sera. Joumal of Clinical Imestigation 58, 1163-1173.

Veale, D. R., SMIth, H., WITt, K. \& Marshall, R. B. (1975). Differential ability of colonial types of Neisseria gonorrhoeae to produce infection and an inflammatory response in subcutaneous perforated plastic chambers in guinea pigs and rabbits. Joumal of Medical Microbiology 8, 325-335.

Veale, D. R., Penn, C. W., Parsons, N. J. \& Smith, H. (1980). Preliminary studies of a factor in guinea pig serum which induces serum resistance in Neisseria gonorrhoeae. Society for General Microbiology Quarterly 7, 188.

Veale, D. R., PENN, C. W. \& Sutrh, H. (1981). Factors affecting the induction of phenotypically determined serum resistance of Neisseria gonorrhoeae grown in media containing serum or its diffusible components. Joumal of General Microbiology 122, 235-245.

WARD, M. E., WaTT, P. J. \& GlYNN, A. A. (1970). Gonococci in urethral exudates possess a virulence factor lost on subculture. Nature, London 227, 382384.

Weiss, J. B., Lote, C. J. \& Bobinski, H. (197I). New low molecular weight glycopeptide containing triglucosylcysteine in human erythrocyte membrane. Nature New Biology 234, 25-26. 